698

The Open Dentistry Journal

RESEARCH ARTICLE

\title{
A Comparative Study of Surface Hardness between Two Bioceramic Materials in an Experimental Apexification Model under Wet and Dry Conditions
}

\author{
Maria Priya Paul ${ }^{1}$, Swathi Amin ${ }^{1}$, Arun Mayya ${ }^{1, *}$, Rajaram Naik ${ }^{1}$ and Shreemathi S. Mayya ${ }^{2}$ \\ ${ }^{1}$ Department of Conservative Dentistry and Endodontics, AJ Institute of Dental Sciences, Kuntikana, Mangalore \\ ${ }^{2}$ Department of Data Science, Prasanna School of Public Health, Manipal Academy of Higher Education, Manipal, India
}

\begin{abstract}
:
Background:

The placement of a wet cotton pellet against Mineral Trioxide Aggregate (MTA) is often recommended to ensure the completion of its setting reaction.

\section{Objective:}

This study aimed to evaluate the setting behaviour of MTA Angelus and NeoMTA by comparing their hardness after placing them in dry and moist conditions.

\section{Methodology:}

A simulated open apex was created on 40 polyvinyl tubes. The apical $4 \mathrm{~mm}$ of the tubes was filled with the two materials, NeoMTA Plus (Avalon Biomed Inc. Bradenton, FL, USA) and MTA Angelus (Angelus, Londrina, PR, Brazil) ( $\mathrm{n}=20$ per group). Both groups were subdivided into two subgroups based on the dry and wet conditions ( $n=10$ per group). A wet cotton pellet was placed above the two materials in the wet group, and the coronal segment was sealed using Type II Glass ionomer cement (GC corporation Tokyo, Japan). Gutta-percha was placed against the test materials in the dry group with the coronal segment sealed with amalgam. Samples were placed in an oasis soaked in phosphate-buffered saline for seven days in $100 \%$ humidity and at $37^{\circ} \mathrm{C}$. Microhardness was measured independently at 4 and 2 mm from the apex. Hardness was compared
\end{abstract} between materials and conditions, applying analysis of variance $(\mathrm{a}=.05)$.

Results:

The presence of dry or wet conditions had no significant effect on material hardness. MTA Angelus showed significantly higher hardness values compared with NeoMTA Plus.

\section{Conclusion:}

The moisture of the periapical environment can compensate for the absence of a wet cotton pellet and is adequate for the setting of the materials.

Keywords: Apexification, Microhardness, Mineral trioxide aggregate, Hardness, Analysis of variance, Wet cotton pellet.

\begin{tabular}{|l|l|l|l|}
\hline Article History & Received: September 20, 2020 & Revised: November 26, 2020 & Accepted: December 16, 2020
\end{tabular}

\section{INTRODUCTION}

Apexification is the procedure used to create a calcified barrier at the apex of a nonvital tooth with an immature apex. The main objective of apexification is the formation of a calcific barrier at the apex without any apparent pathosis to induce root-end closure [1]. Calcium hydroxide has been in use to stimulate the apical barrier formation in an immature necrotic tooth to allow for ensuing obturation. Direct creation

\footnotetext{
* Address correspondence to this author at the Department of Conservative Dentistry and Endodontics, AJ Institute of Dental Sciences, Kuntikana, Mangalore; Tel: 9742727324; E-mail: mayya.arun@gmail.com
}

of the apical barrier can be achieved with modern materials, some of which integrate moisture in their setting reaction. These, in turn, reduce the duration of treatment while avoiding the extended use of calcium hydroxide, which has been linked with increasing the risk of root fracture by weakening the dentin [2].

Bioceramics have given us the hope of generating engineered human tissues, and this has revolutionized the field of medicine [3].

In recent times, mineral trioxide aggregate (MTA) has achieved massive acceptance for use in apexification 
procedures. The apical hard tissue formed with MTA has a significantly superior consistency compared to that formed with calcium hydroxide. It also helps in the formation of bone and periodontium around its interface.

MTA Angelus (Angelus, Londrina, PR, Brazil) is one of the most multifaceted materials in the world of dentistry of this century. It has shown excellent biocompatibility and has excellent potential in endodontic use [4].

NeoMTA Plus (Avalon Biomed Inc. Bradenton, FL, USA) is a new tricalcium silicate material with the radio-opacifier tantalum oxide $\left(\mathrm{Ta}_{2} \mathrm{O}_{5}\right)$. This is combined with a water-based gel for improved handling properties. A thin consistency of the material can be used as an orthograde sealer or a thicker consistency for root-end filling [5].

MTA is a powder that contains calcium silicate and consists of hydrophilic particles, which causes setting under humidity conditions. The hydrophilic MTA thus requires moisture to set. Previous studies have shown that the cement has improved flexural strength when the setting reaction takes place in the presence of moisture [4]. MTA Angelus and NeoMTA differ mainly in their opacifier composition, with the presence of bismuth oxide in the former and tantalum oxide in the latter $[6,7]$.

The manufacturers of MTA Angelus and NeoMTA have recommended placing a wet cotton pellet against these materials to ensure the completion of the setting reaction. Although few studies have stated that the periapical interstitial fluid provides enough moisture for the condensed apical plug to become hard enough, the absorption of moisture by MTA Angelus and NeoMTA from the adjacent periapical environment allows the setting reaction to occur [8].
The various fundamental material properties such as tensile strength, elastic modulus, the stability of crystal structure, and yield strength significantly influence the microhardness of a material. Thus, in comparison with baseline information, microhardness can be used as a barometer to measure the strength and resistance to deformation and the setting process. It can also suggest the influence the different setting environments have on the material strength [9]. Vickers hardness test is an indicator of the quality and progress of the setting reaction as well as the strength of calcium silicate-based material.

Therefore, this study aimed to evaluate the setting behaviour of MTA Angelus and NeoMTA by comparing their hardness after placing in dry and moist conditions.

\section{MATERIALS AND METHODS}

The study was approved by the institutional ethics committee. Forty polyvinyl plastic tubes were used as the experimental apexification models. A simulated open apex was created in these polyvinyl tubes. The apical $4 \mathrm{~mm}$ of the tubes was filled with the two materials, NeoMTA and MTA Angelus ( $\mathrm{n}=20$ per group). Both groups were divided into two subgroups based on dry and wet conditions ( $\mathrm{n}=10$ per group), as shown in Fig. (1).

According to the instructions by the manufacturers, the materials in both the groups were mixed. Suitable consistency for MTA Angelus was achieved by using a 3:1, powder to water ratio. For NeoMTA Plus, one scoop ( $0.05 \mathrm{gm}$ or $0.1 \mathrm{gm})$ was dispensed on a non-absorbent pad. NeoMTA Plus gel was dispensed as a streak $(12-20 \mathrm{~mm})$ next to the powder. A puttylike consistency was achieved by gradually adding the gel into the powder and spatulation of the powder/gel mixture firmly against the glass slab to wet the powder by the gel thoroughly.

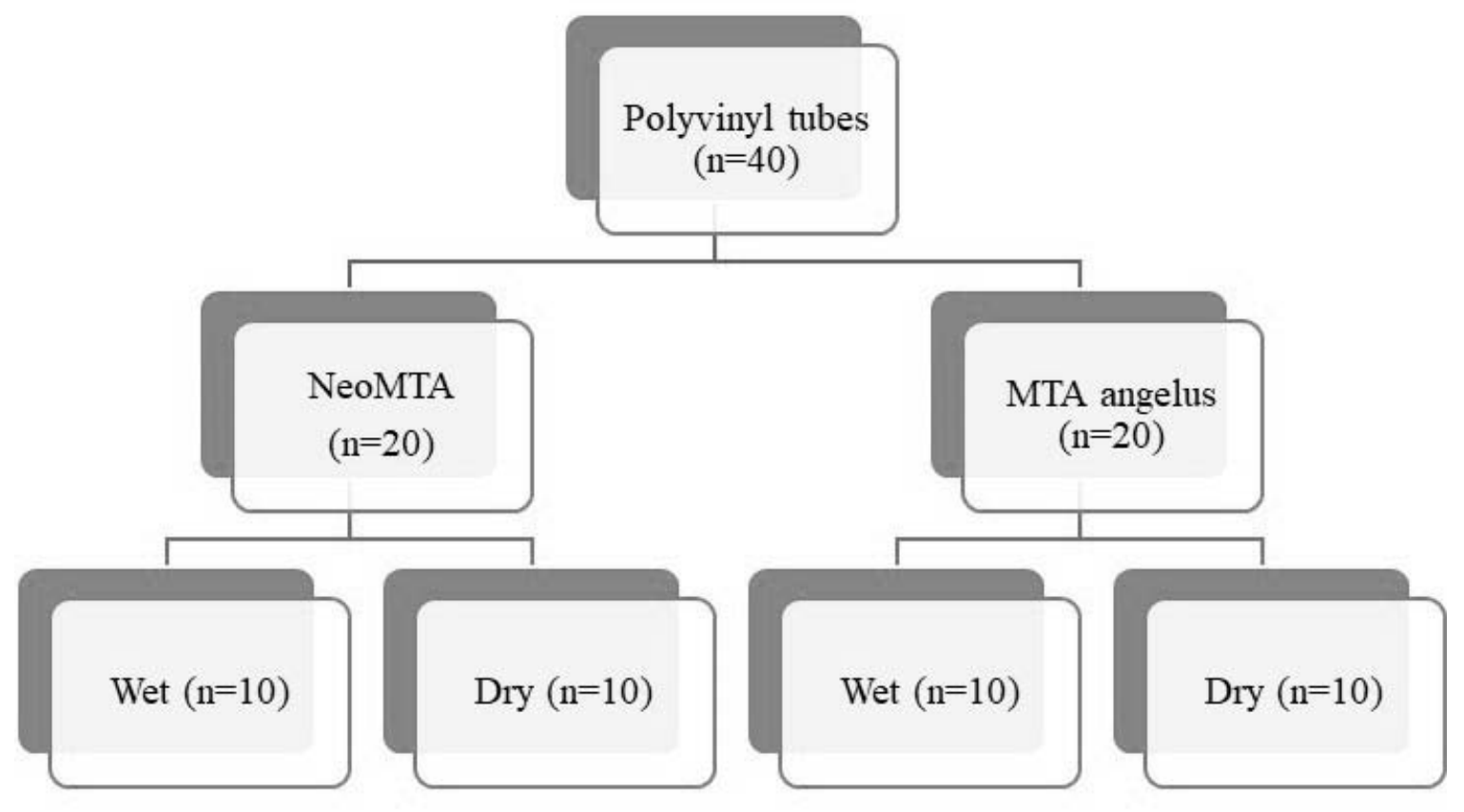

Fig. (1). Distribution of polyvinyl tubes to NeoMTA and MTA angelus groups and dry and wet conditions. 


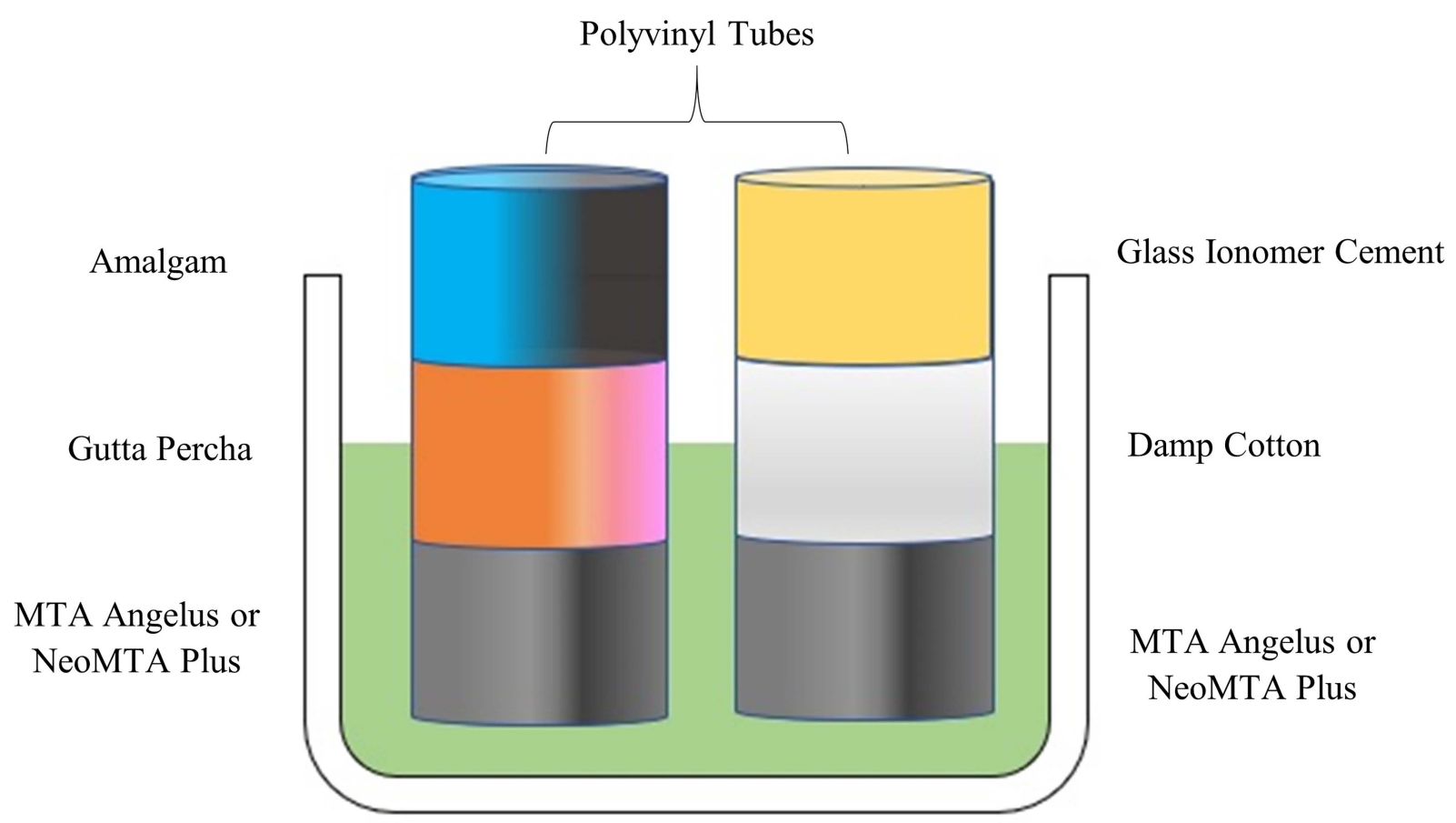

Fig. (2). Schematic representation of the experimental apexification model.

Once mixed, MTA Angelus and NeoMTA Plus were inserted individually as increments into polyvinyl plastic tubes of internal diameter $2 \mathrm{~mm}$ and height $10 \mathrm{~mm}$ using an amalgam carrier. The materials were inserted into the tubes $4 \mathrm{~mm}$ from the proposed apex followed by vertical compaction using \#80 endodontic plugger (GDC Germany stainless steel CE \# RCP). Subsequent procedures were carried out after a waiting period of 11-15 minutes for the initial setting of the material.

In groups simulating wet conditions, the surface of both materials was covered with a damp cotton pellet, following which Type II Glass ionomer cement (GC corporation Tokyo, Japan) was used to seal the coronal portion resembling multiple visits. In groups simulating dry conditions, thermoplasticized gutta-percha bars (Denjoy, Hunan province, China) were directly placed on the surface of both the materials using vertical compaction. Amalgam was then used to coronally seal the material as done in a single visit procedure.

Simulation of periapical tissue conditions was done by placing all the samples on a porous oasis saturated with phosphate buffering saline (Fig. 2). These samples, along with the oasis, were kept at $37^{\circ} \mathrm{C}$ in $100 \%$ humidity for seven days. Diamond discs $(0.25 \mathrm{~mm})$ were used to section the tubes after their removal from the oasis. Sectioning was done at the junction of the gutta-percha and test material in groups simulating dry conditions. Groups simulating wet conditions were sectioned between the cotton pellet and test material. Samples were then mounted on acrylic moulds, following which it was sequentially polished with 600 and 2000 grit silicon carbide papers and pumice paste. The samples were then subjected to Vickers microhardness testing (TEC-SOL, India). The test was done at 2 and $4 \mathrm{~mm}$ from the proposed apex. A square diamond pyramid indenter with a face angle of $136^{\circ}$ and a load of $100 \mathrm{gm}$ for ten seconds was used to perform the test. The formula $\mathrm{HV}=0.1891\left[\mathrm{~F} / \mathrm{d}^{2}\right]$ was used to calculate the hardness.

\subsection{Statistical Analysis}

Analysis of variance (ANOVA) model was used to analyze the influence of different materials and conditions on the hardness.

\section{RESULTS}

Figs. (3 and 4) show mean microhardness of the two materials in dry and wet conditions. The initial 3-way ANOVA model showed that the interaction between material and condition $(\mathrm{F} 1,72=0.34, \mathrm{P}=0.561)$ as well as material and level ( $\mathrm{F} 1,72=0.82, \mathrm{P}=.367$ ) were not significant. A 2-way ANOVA model showed a significant effect for "material". Microhardness of MTA Angelus was significantly higher compared to NeoMTA (F 1,76 $=6.44, \mathrm{P}=0.013$ ). Hardness of the materials did not differ significantly in dry and wet "condition" ( $\mathrm{F} 1,76=1.10, \mathrm{P}=.297)$.

\section{DISCUSSION}

According to the American Association of Endodontists, apexification is the "method to induce a calcified barrier in a root with an open apex or the continued apical development of teeth with incomplete roots and necrotic pulp."

The first choice material to achieve apexification has been Calcium Hydroxide, which requires 5-20 months and repeated applications for inducing the formation of a calcific barrier. The long course of this treatment includes several obstacles such as the dislodgement of the temporary restoration, increased chances of re-infection as well as the requisite highlevel patient compliance. To overcome this, a single visit apexification procedure has been proposed [10]. 


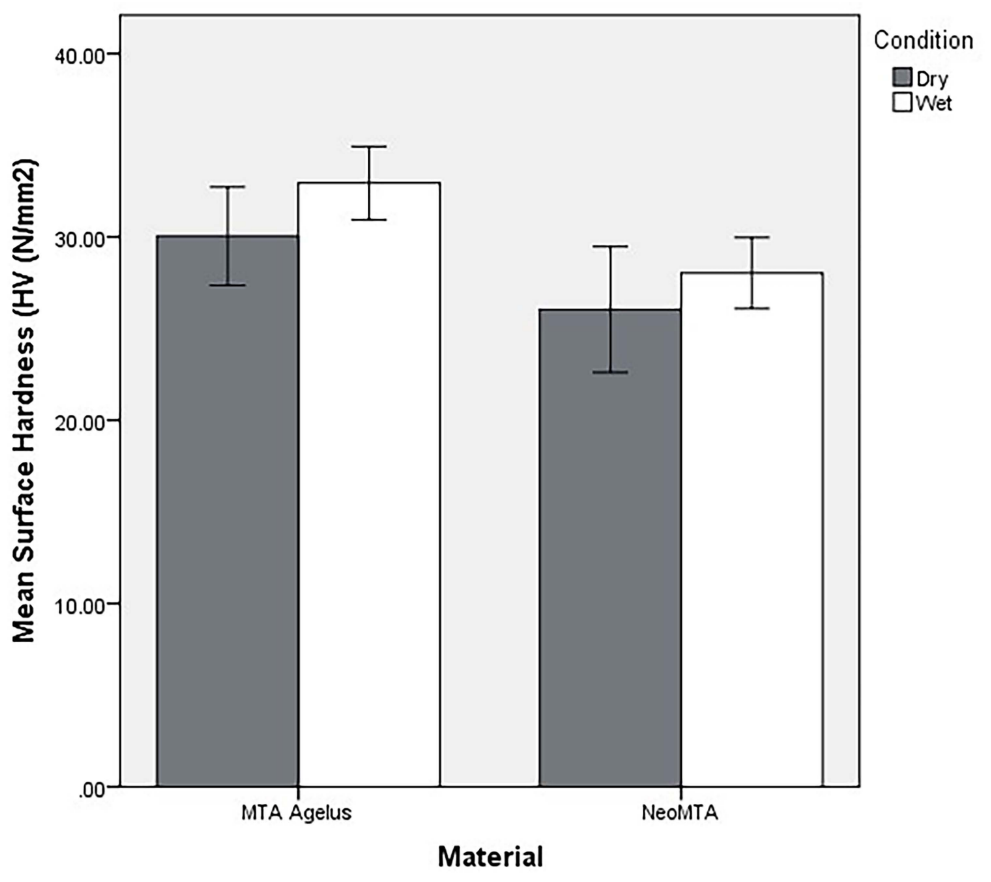

Fig. (3). Microhardness at $2 \mathrm{~mm}$ from the proposed apex (Error bars 95\% CI).

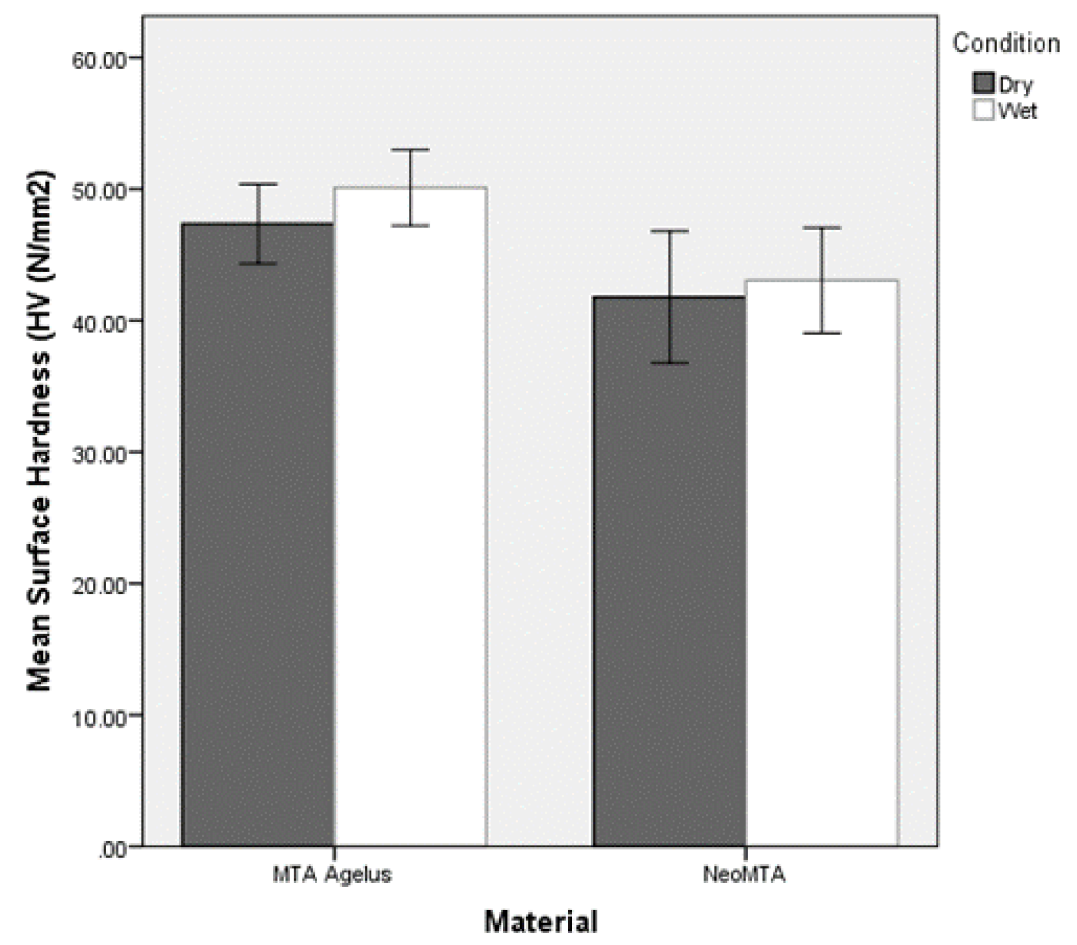

Fig. (4). Microhardness at $4 \mathrm{~mm}$ from the proposed apex (Error bars 95\% CI).

MTA, when used for root-end filling, has a favourable sealing ability while being biocompatible and bacteriostatic. It is thus considered a suitable material for a single visit apexification [10].

The manufacturers recommend placing a wet cotton pellet for the correct setting and maturation of MTA. According to the manufacturers, the setting time of MTA angelus is 15 minutes, and that of NeoMTA Plus is 315 minutes $[11,12]$.
Various authors have suggested that the structural maturation of MTA can range between 2.5 hours to 21 days, continuing well past the setting time clinically defined by the manufacturers [13 - 17]. The retrieval of the cotton pellet and placing a permanent restoration will always require a second appointment, which may have implications for both cost and comfort [18].

However, several studies have also claimed that the 
absorption of moisture from the periapical environment via accessory canals and cementum may be adequate to allow MTA to set [19].

A chemical reaction between the cement and water is initiated when MTA meets water. This is the primary setting reaction called a hydration reaction. Although the presence of moisture has been recommended to allow sufficient setting of MTA, the amount of moisture required for achieving maximum beneficial properties is still up for debate [20].

According to the present study, the microhardness of MTA Angelus was significantly higher compared to NeoMTA in both dry and wet conditions at both the levels (2 and $4 \mathrm{~mm}$ from the apex). The microhardness of the two materials, however, was not significantly influenced by either dry or wet conditions. Despite the recommendation to keep a moistened cotton pellet from the intracanal side for the complete set of the material, the materials could set in the dry condition due to the fluid present in the periapical environment which was sufficient in providing the moisture required for the setting of the materials.

In the current study, polyvinyl tubes were used to replicate canals of internal diameter $2 \mathrm{~mm}$ and length $10 \mathrm{~mm}$. MTA was placed $4 \mathrm{~mm}$ from the proposed apex in both groups as done in a previous study by Hachmeister DR et al. They had concluded that increased resistance to displacement is achieved by a $4 \mathrm{~mm}$ apical barrier than $1 \mathrm{~mm}$, suggesting that the MTA thickness directly affects its displacement, hardness, and sealing ability $[21,22]$.

In the MTA Angelus and NeoMTA dry groups, guttapercha was placed immediately after placing the materials, followed by amalgam as a permanent restoration as it would in a single visit apexification. In the MTA Angelus and NeoMTA wet groups, the wet cotton pellet was placed above the material, followed by type II GIC as temporary restoration as done in a two-visit apexification procedure.

According to Menkin et al., normal tissue $\mathrm{pH}$ in humans falls within a range of 7.2 to 7.4 , being slightly alkaline [23]. In the current study, an oasis soaked in phosphate-buffered saline (PBS), a synthetic tissue fluid, was used to simulate the periapical environment. PBS has a constant $\mathrm{pH}$ of 7.4 [24]. The ends of all the samples, which mimicked the apical region, were inserted into the oasis. To simulate clinical conditions, the specimens were incubated at $37^{\circ} \mathrm{C}$ and $100 \%$ humidity for seven days. Richard A et al., showed that MTA had higher resistance to displacement at seven days when compared to 24 and 72 hours. This suggests MTA was still setting after the first 24 or 72 hours [25].

The measurement of hardness at $4 \mathrm{~mm}$ from the proposed apex helps determine whether moisture from the periapical environment was sufficient for the complete hydration and maturation of the material. The hardness measurement at $2 \mathrm{~mm}$ from the proposed apex is carried out to confirm the absorption of moisture by the central core of the material to achieve internal hardness. The results indicated that microhardness between the two materials (NeoMTA and MTA Angelus) was statistically not significant in both wet and dry conditions at 2 and $4 \mathrm{~mm}$ from the proposed apex (Table 1).
Table 1. Materials, conditions, and surface microhardness from Vickers hardness testing (*) at two different levels.

\begin{tabular}{|c|c|c|c|c|c|}
\hline Group & $\mathbf{n}$ & Material & Condition & \begin{tabular}{|c|}
$\mathrm{HV}\left(\mathrm{Kg} / \mathrm{mm}^{2}\right)$ \\
$2 \mathrm{~mm} *$ \\
\end{tabular} & \begin{tabular}{|c|}
$\mathrm{HV}\left(\mathrm{Kg} / \mathrm{mm}^{2}\right)$ \\
$4 \mathrm{~mm}^{*}$ \\
\end{tabular} \\
\hline 1 & 10 & MTA Angelus & Dry & $30.04 \pm 3.76$ & $47.35 \pm 4.23$ \\
\hline 2 & 10 & MTA Angelus & Wet & $32.94 \pm 2.79$ & $50.10 \pm 4.04$ \\
\hline 3 & 10 & NeoMTA & Dry & $26.04 \pm 4.80$ & $41.78 \pm 6.99$ \\
\hline 4 & 10 & NeoMTA & Wet & $28.03 \pm 2.72$ & $43.05 \pm 5.61$ \\
\hline
\end{tabular}

The findings of our study indicated that both MTA Angelus and NeoMTA Plus absorb moisture from the periapical surroundings for completing the setting reaction. Hence, in clinical conditions, the permeability of the cementum and the presence of accessory canals allow the seepage of the interstitial fluid, thereby allowing hydration and maturation of the materials [19]. Thus, within the limitations of this study, it is possible to perform apexification procedures in a single visit.

\section{CONCLUSION}

The hardness of the materials remained unaffected in wet and dry conditions. The setting of either of the materials does not require the presence of a wet cotton pellet. MTA Angelus displayed a higher hardness in both the environments compared to NeoMTA. The use of both materials in either wet or dry environments can thus be accepted for a single visit apexification procedure.

\section{ETHICS APPROVAL AND CONSENT TO PARTI- CIPATE}

This study was approved by the Ethics Committee of AJ Institute of Dental Sciences (AJEC/REV/170/2019).

\section{HUMAN AND ANIMAL RIGHTS}

Not applicable.

\section{CONSENT FOR PUBLICATION}

Not applicable.

\section{AVAILABILITY OF DATA AND MATERIALS}

The data that support the findings of this study are available from the corresponding author, [SSM], upon reasonable request.

\section{FUNDING}

None.

\section{CONFLICT OF INTEREST}

The authors declare no conflict of interest, financial or otherwise.

\section{ACKNOWLEDGEMENTS}

We acknowledge the Department of Dental Materials, Yenepoya Dental College, Yenepoya University for providing the Vickers Hardness Tester for the study. 


\section{REFERENCES}

[1] Rafter M. Apexification: A review. Dent Traumatol 2005; 21(1): 1-8. [http://dx.doi.org/10.1111/j.1600-9657.2004.00284.x] [PMID: 15660748]

[2] Caronna V, Himel V, Yu Q, Zhang JF, Sabey K. Comparison of the surface hardness among 3 materials used in an experimental apexification model under moist and dry environments. J Endod 2014; 40(7): 986-9.

[http://dx.doi.org/10.1016/j.joen.2013.12.005] [PMID: 24935549]

[3] Best SM, Porter AE, Thian ES, Huang J. Bioceramics: Past, present and for the future. J Eur Ceram Soc 2008; 28: 1319-27.

[http://dx.doi.org/10.1016/j.jeurceramsoc.2007.12.001]

[4] Tawil PZ, Duggan DJ, Galicia JC. Mineral trioxide aggregate (MTA): Its history, composition, and clinical applications Compend Contin Educ Dent 2015; 36: 247-52.

[5] Torabinejad M, Parirokh M, Dummer PMH. Mineral trioxide aggregate and other bioactive endodontic cements: An updated overview - part II: other clinical applications and complications. Int Endod J 2018; 51(3): 284-317. [http://dx.doi.org/10.1111/iej.12843] [PMID: 28846134]

[6] Coaguila-Llerena H, Ochoa-Rodriguez VM, Castro-Núñez GM, Faria G, Guerreiro-Tanomaru JM, Tanomaru-Filho M. Physicochemical properties of a bioceramic repair material - BioMTA. Braz Dent J 2020; 31(5): 511-5.

[http://dx.doi.org/10.1590/0103-6440202003163] [PMID: 33146335]

[7] Khalil I, Naaman A, Camilleri J. Properties of tricalcium silicate sealers. J Endod 2016; 42(10): 1529-35.

[http://dx.doi.org/10.1016/j.joen.2016.06.002] [PMID: 27523906]

[8] Gong J, Wang J, Guan Z. A comparison between knoop and vickers hardness of silicon nitride ceramics. Mater Lett 2002; 56: 941-4. [http://dx.doi.org/10.1016/S0167-577X(02)00641-9]

[9] Namazikhah MS, Nekoofar MH, Sheykhrezae MS, et al. The effect of $\mathrm{pH}$ on surface hardness and microstructure of mineral trioxide aggregate. Int Endod J 2008; 41(2): 108-16. [PMID: 18042226]

[10] Pace R, Giuliani V, Pini Prato L, Baccetti T, Pagavino G. Apical plug technique using mineral trioxide aggregate: results from a case series. Int Endod J 2007; 40(6): 478-84.

[http://dx.doi.org/10.1111/j.1365-2591.2007.01240.x] [PMID: 17403040]

[11] Siboni F, Taddei P, Prati C, Gandolfi MG. Properties of NeoMTA Plus and MTA Plus cements for endodontics. Int Endod J 2017; 50(Suppl. 2): e83-94.

[http://dx.doi.org/10.1111/iej.12787] [PMID: 28452115]

[12] Saghiri MA, Orangi J, Asatourian A, et al. Calcium silicate-based cements and functional impacts of various constituents. Dent Mater J 2017; 36(1): 8-18.

[http://dx.doi.org/10.4012/dmj.2015-425] [PMID: 27773894]

[13] Malhotra N, Agarwal A, Mala K. Mineral trioxide aggregate: Part 2 - a review of the material aspects. Compend Contin Educ Dent 2013;
34(3): e38-43. [PMID: 23631637]

[14] Magura ME, Kafrawy AH, Brown CE Jr, Newton CW. Human saliva coronal microleakage in obturated root canals: An in vitro study $\mathrm{J}$ Endod 1991; 17(7): 324-31.

[http://dx.doi.org/10.1016/S0099-2399(06)81700-0] [PMID: 1779218]

[15] Witherspoon DE, Small JC, Regan JD, Nunn M. Retrospective analysis of open apex teeth obturated with mineral trioxide aggregate. J Endod 2008; 34(10): 1171-6.

[http://dx.doi.org/10.1016/j.joen.2008.07.005] [PMID: 18793914]

[16] Roberts HW, Toth JM, Berzins DW, Charlton DG. Mineral trioxide aggregate material use in endodontic treatment: A review of the literature. Dent Mater 2008; 24(2): 149-64.

[http://dx.doi.org/10.1016/j.dental.2007.04.007] [PMID: 17586038]

[17] Chedella SC, Berzins DW. A differential scanning calorimetry study of the setting reaction of MTA. Int Endod J 2010; 43(6): 509-18. [http://dx.doi.org/10.1111/j.1365-2591.2010.01708.x] [PMID: 20536579]

[18] Eid AA, Komabayashi T, Watanabe E, Shiraishi T, Watanabe I. Characterization of the mineral trioxide aggregate-resin modified glass ionomer cement interface in different setting conditions. J Endod 2012; 38(8): 1126-9.

[http://dx.doi.org/10.1016/j.joen.2012.04.013] [PMID: 22794220]

[19] Budig CG, Eleazer PD. In vitro comparison of the setting of dry ProRoot MTA by moisture absorbed through the root J Endod 2008; 34(6): 712-4.

[http://dx.doi.org/10.1016/j.joen.2008.03.004] [PMID: 18498896]

[20] Walker MP, Diliberto A, Lee C. Effect of setting conditions on mineral trioxide aggregate flexural strength. J Endod 2006; 32(4): 334-6.

[http://dx.doi.org/10.1016/j.joen.2005.09.012] [PMID: 16554206]

[21] Hachmeister DR, Schindler WG, Walker WA III, Thomas DD. The sealing ability and retention characteristics of mineral trioxide aggregate in a model of apexification. J Endod 2002; 28(5): 386-90. [http://dx.doi.org/10.1097/00004770-200205000-00010] [PMID: 12033201]

[22] Kumar V, Zameer M, Prasad V, Mahantesh T. Boon of MTA apexification in young permanent posterior teeth. Case Rep Dent 2014; 2014673127

[http://dx.doi.org/10.1155/2014/673127] [PMID: 25431690]

[23] Menkin V. Biochemical mechanisms in inflammation. BMJ 1960; 1(5185): 1521-8.

[http://dx.doi.org/10.1136/bmj.1.5185.1521] [PMID: 20788900]

[24] Sarkar NK, Caicedo R, Ritwik P, Moiseyeva R, Kawashima I. Physicochemical basis of the biologic properties of mineral trioxide aggregate. J Endod 2005; 31(2): 97-100.

[http://dx.doi.org/10.1097/01.DON.0000133155.04468.41] [PMID: 15671817]

[25] Vanderweele RA, Schwartz SA, Beeson TJ. Effect of blood contamination on retention characteristics of MTA when mixed with different liquids. J Endod 2006; 32(5): 421-4.

[http://dx.doi.org/10.1016/j.joen.2005.09.007] [PMID: 16631840]

(C) 2020 Paul et al.

This is an open access article distributed under the terms of the Creative Commons Attribution 4.0 International Public License (CC-BY 4.0), a copy of which is available at: (https://creativecommons.org/licenses/by/4.0/legalcode). This license permits unrestricted use, distribution, and reproduction in any medium, provided the original author and source are credited. 